\title{
Inherent Challenges in the Management of Neonatal Giant Occipital Encephalocele. A Case Series
}

\author{
Akshay Baid $^{(1)}$, Anuj Kumar Tripathi ${ }^{(2)}$, Prateek Bansal ${ }^{(1)}$, Syamantak \\ Srivastava $^{(1)}$, Sahil Sharma ${ }^{(1)}$, Yashpal Monga ${ }^{(3)}$ \\ ${ }^{I}$ Junior Resident-III, Department Of General Surgery. \\ ${ }_{2}^{2}$ (M.Ch) Assistant Professor, Neurosurgery Division Of Department Of General Surgery \\ ${ }^{3}$ (M.Ch) Professor \& Head, Plastic Surgery Division Of Department Of General Surgery
}

\begin{abstract}
Encephalocele are not uncommon but giant encephaloceles are rare lesions. Giant encephalocele mean they are larger than the head. These defects in the formation of the cranium are often associated with congenital anomalies of the brain and/or meninges. The defect is often on the squamous part of the occipital bone and may include the posterior part of the foramen magnum They contain herniated cranial contents inside the skin covering sac through congenital defect in the skull bone. Because of their enormous size they create a surgical challenge. Here we are reporting a case series of neonatal giant occipital encephalocele.
\end{abstract}

Keywords : Giant encephalocele, management, hydrocephalus, occipital encephalocele.

\section{Introduction}

Neonatal giant encephaloceles are rare with incidence of $3.6 \%$ with occipital predominance [1]. Giant encephaloceles means encephaloceles that are larger than the skull. The defect is usually present in the occipital bone and sac may contain meninges, brain or both [1]. Majority of occipital encephaloceles are seen in female. Hydrocephalus is seen in half of the cases of giant occipital encephaloceles [1]. They are associated with other congenital abnormalities like microgyria, polygyria, craniostenosis, microcephaly and micrognathia $[1,2]$.

\section{Case Report - 1}

A 3 days old male baby presented with a swelling over the occipital region since birth. The baby was born at 37 weeks of gestation by caesarean section with a birth weight of 3100 gms. There was no abnormality on physical examination except for a large cystic mass in occipital region. The mass was larger than the size of the head. Routine hematological and biochemical investigations were normal. Computed tomography of head revealed occipital bony defect of size $14 \mathrm{~mm}$ with evidence of meningo-encephalocele and herniation of cerebellum into the upper cervical region with moderate hydrocephalus.

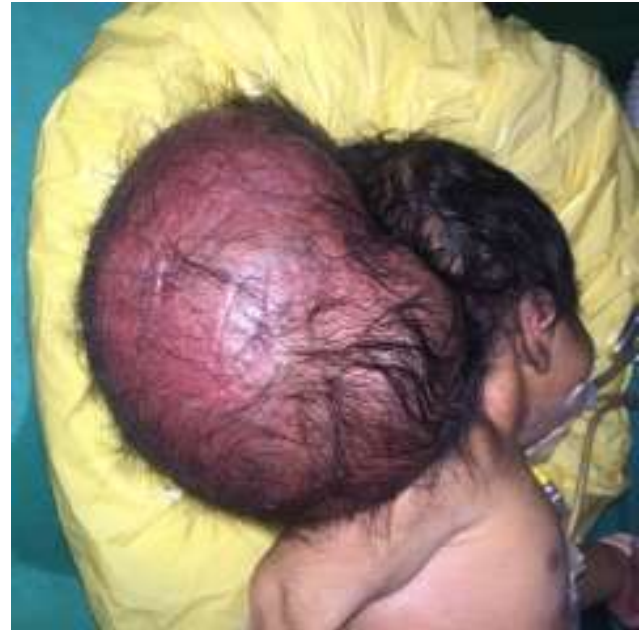

Pre-Operative Image Showing Giant Occipital Encephalocele

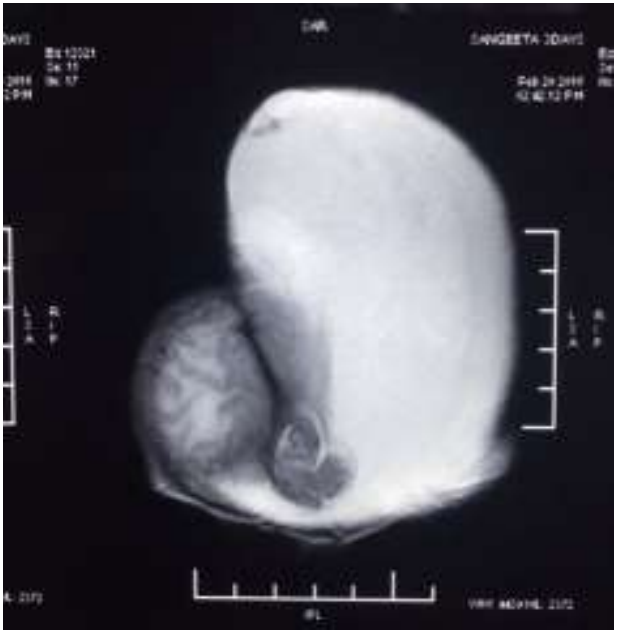

Pre-Operative Mri Image Showing Giant Occipital Encephalocele

Magnetic resonance imaging of brain was suggestive of $18 \times 13 \mathrm{~mm}$ defect in occipital bone with occipital encephalocele along with brainstem kinking, descent of sinus confluence and small posterior fossa. Syringohydromyelia was also present in upper cervical canal. 


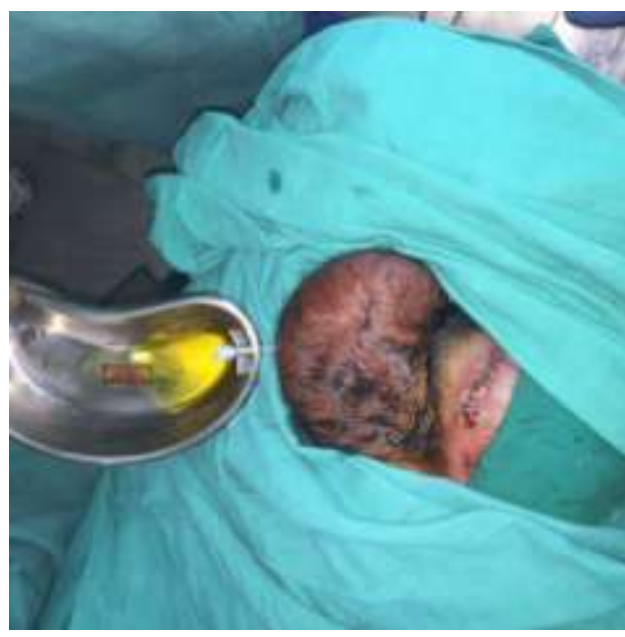

Intra-Operative Image During Aspiration

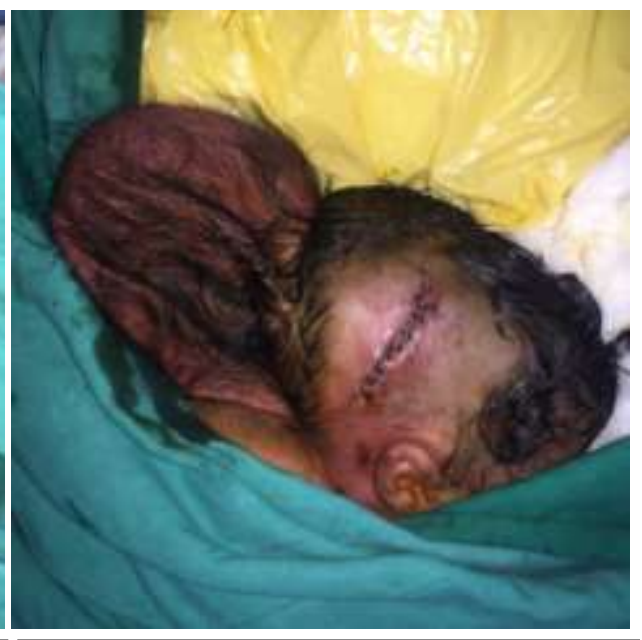

Intra-Operative Image After V-P Shunting

Surgery was planned. Anesthesia was given. Firstly, ventriculo-peritoneal shunt was placed from right parietal region. The occipital swelling was then canulated with a wide bore needle and around $600 \mathrm{ml}$ was drained out gradually following which the swelling got reduced. Post drainage, Arterial blood gas analysis was done. Patient was then turned to prone position. Incision was given in the sac. Gliosed part of cerebellum was excised. Sinus was preserved. Redundant skin and the sac was excised. Hemostasis was achieved, followed by water tight closure of the sac done. Closure was done in layers. Post-op period was uneventful and patient was discharged on post-op day 7.

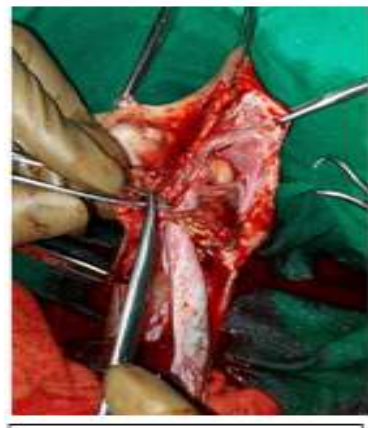

Intra-Operative Image

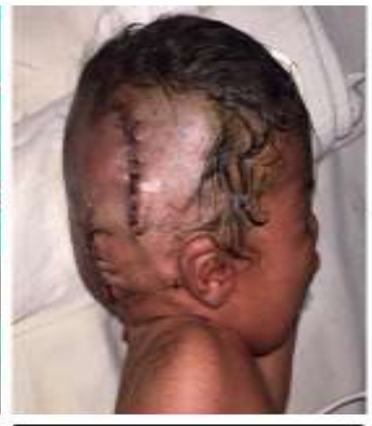

Post-Operative Image

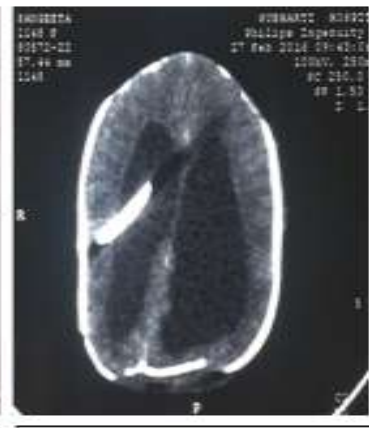

Post-Operative Image With V-P Shunt Insitu

III. Case Report - 2

A 17 days old male baby presented with swelling over occipital region since birth. The baby was born at 37 weeks of gestation by caesarean section with a birth weight of 3900 gms. No any other neurological deficit present. There was no abnormality on physical examination except for a large cystic mass in occipital region. The mass was larger than the size of the head. Routine investigations were normal.

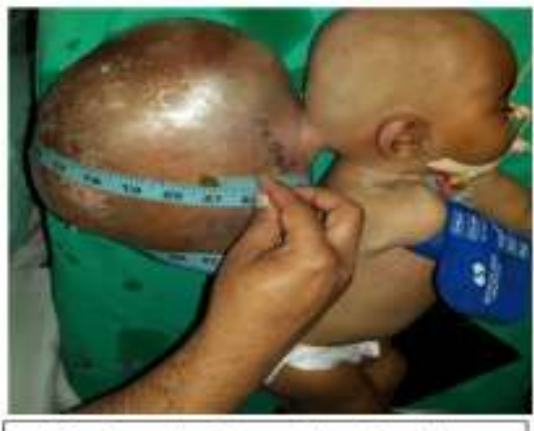

Pre-Operative Image Showing Giant Occipital Encephalocele

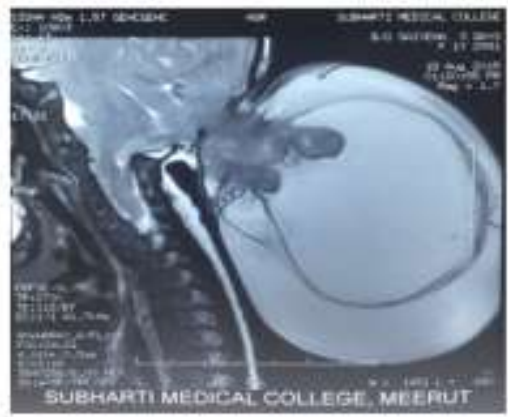

Pre-Operative Mri Image Showing Giant Oceipital Encephalocele 
Magnetic resonance imaging revealed $18 \times 16 \mathrm{~mm}$ defect in occipital bone with occipital encephalocele along with brainstem kinking, descent of sinus confluence and small posterior fossa with altered configuration of bilateral lateral and $3^{\text {rd }}$ ventricles. Surgery was planned. Occipital swelling was first canulated with a wide bore needle and around $900 \mathrm{ml}$ was drained out gradually. Patient was then intubated in left lateral position.

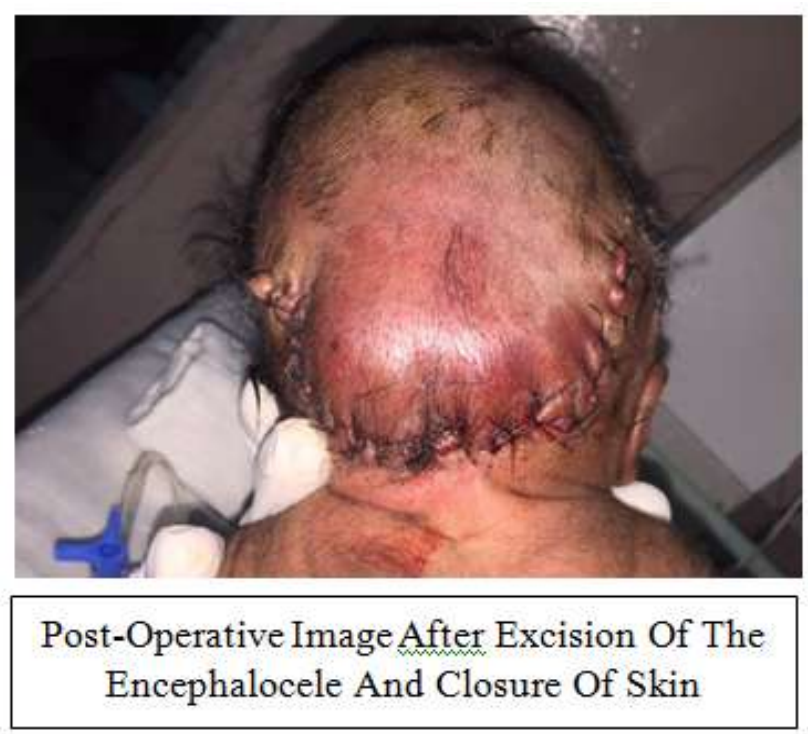

Sac was opened. Gliosed part excised. Sinus was preserved. Redundant skin and sac was excised. During intra-op patient developed cardiac arrest. CPR was started and patient was revived. Post-op period was uneventful and patient was discharged on post-op day 10.

\section{Case Report - 3}

A 19 days female baby came with swelling over the occipital region since birth. The baby was born out of 36 weeks of gestation by caesarean section with a birth weight of 3800 gms. The swelling was larger than the size of head. No any other abnormality detected. Neurological examination was normal. Magnetic resonance imaging revealed 16×14 mm defect in occipital bone with occipital encephalocele along with brainstem kinking, descent of sinus confluence and small posterior fossa. Surgery was planned. Patient was intubated in left lateral position. Sac was opened. Gliosed part was excised taking in care of sinus to be preserved. Redundant skin and sac was excised. Closure was done in layers. Patient tolerated the procedure well and was discharged on post-op day 8 .

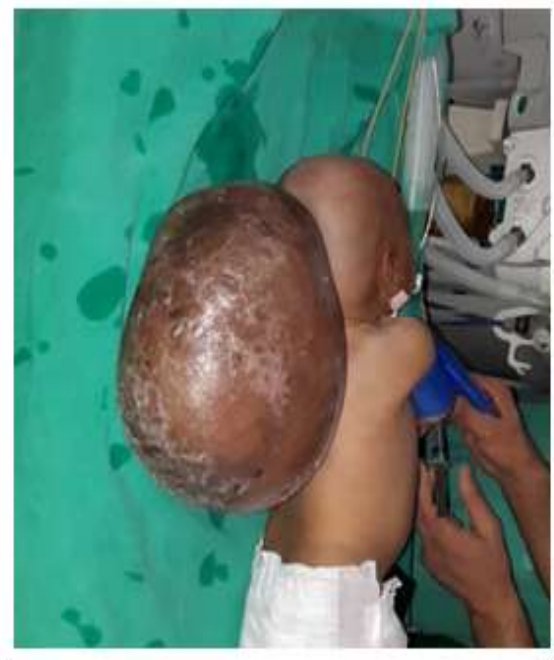

Pre-Operative Image Showing Giant Encephalocele

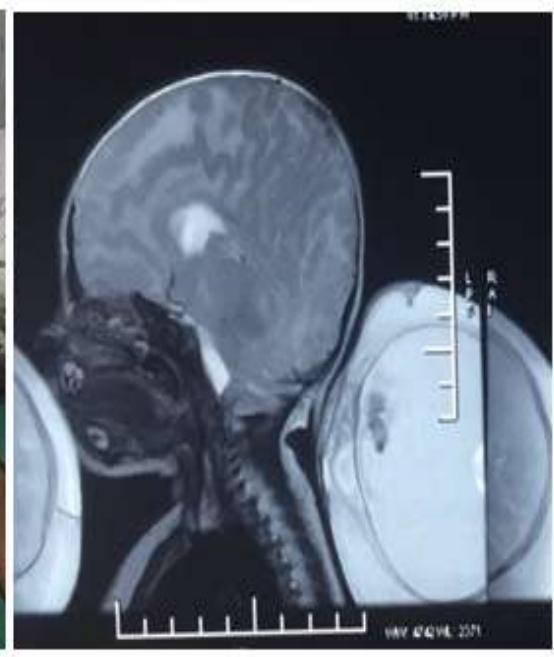

Pre-Operative Mri Image Showing Giant Encephalocele 


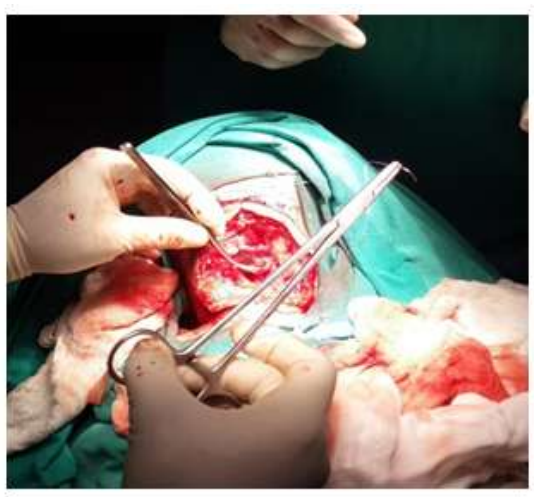

Intra-Operative Image Preserving Viable Brain Matter

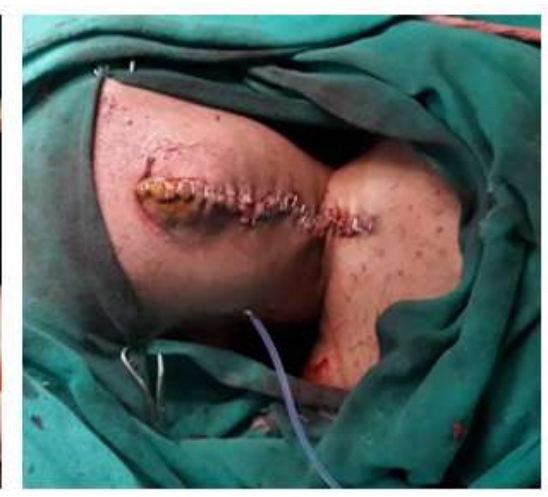

Post-Operative Image After Closure

\section{Discussion}

Encephalocele is a form of neural tube defect and account for 10-20\% of all dysraphism [3]. Anterior encephalocele are more common in male but posterior encephalocele are commonly seen in females.

On review of literature, we found a single case series of giant encephalocele [1]. Hydrocephalus with giant occipital encephalocele is very rare. In Mahapatra series only one neonate with occipital giant encephalocele had hydrocephalus out of three cases [1]. Magnetic resonance imaging of Brain is the investigation of choice in these cases. Computed tomography of head is useful only in detection of bony defect and anatomy but it causes radiation damage in neonates and not useful for soft tissues.

Other anomalies associated with neonatal giant occipital encephalocele are dandy walker cyst $[1,2,4]$. Due to large size of encephalocele, making supine position for endotracheal intubation was difficult. With the help of towel drape we raised the body in such manner that head ring could easily accommodate the encephalocele without compression. Other authors are using different methods for intubation like lateral position [5], placing the child head beyond the table [6], lifting the baby on the table [7] and also aspiration of encephalocele before anesthesia to achieve proper positioning [1].

Surgical expertise is necessary in these cases. Excision of herniated gliosed brain matter with preservation of vital brain structures and viable brain matter along with water tight closure of duramater is necessary for good results. Partial excision of viable brain matter [1], expansile cranioplasty without excision of brain [8] was been used by different authors to achieve good results. Intraoperatively, blood loss, hypothermia, bradycardia and cardiac arrest are well known complications $[9,10,11]$. Therefore patient should be monitored well intra-operatively to prevent such complication which may eventually lead to mortality.

\section{Conclusion}

In neonatal giant occipital encephalocele surgical expertise is necessary and intraoperative blood loss, hypothermia, bradycardia and cardiac complications should be monitored continuosly to achieve better outcomes.

\section{References}

[1]. Mahapatra AK: Giant encephalocele: A study of 14 patients. Pediatr Neurosurg 2011;47:406-411.

[2]. Hokum singh, Daljit singh, DP Sharma, Monica S Tandon, Pragati Ganjoo: Perioperative challenges in patients with giant occipital encephalocele with microcephaly and micrognathia jnrp.2012;3:68-70.

[3]. Chapman PH, Swearingen B, Caviness VS. Subtorcular occipital encephaloceles: Anatomical considerations relevant to operative management. J Neurosurg. 1989;71:375-8.

[4]. Todo T, Usui M, Araki F: Dandy-Walker syndrome forming a giant occipital meningocele-case report. Neurol Med Chir(Tokyo) 1993;33:845-850.

[5]. Bissonnette B. Pediatric neuroanaesthesia: Beyond the theory. In: Badgewell IIM, editor. Clinical Pediatric Anaesthesia. $1^{\text {st }}$ ed. Philadelphia: Lipincott Raven 1997; p 339-45.

[6]. Walia B, Bhargava P, Shandu K. Giant occipital encephalocele. MJAFI 2005;61:293-4.

[7]. Manhas Y, Chinnan NK, Singh AK. Neonatal airway managementin occipital encephalocele. Anesth Analg 2006;103:1632.

[8]. Bozinov O, Tirakotai W, Sure V, Bertalanffy H: Surgical closure and reconstruction of a large occipital encephalocele without parenchymal excision. Childs Nerv Cyst 2005;21:144-147.

[9]. Satyarthee GD, Mahapatra AK: Craniofacial surgery for giant frontonasal encephalocele in neonate. J Clin Neurosci 2002;9:593595.

[10]. Mahapatra AK, Gupta PK, Dev EJ: Posterior fontanelle giant encephalocele. Pediatr Neurosurg 2002;36:40-43.

[11]. Bharti N, Dash HH, Mahapatra AK: Recurrent bradycardia and delayed recovery in a neonate following repair of nasofrontal encephalocele with hosopresencephaly and single cerebral ventricle. J Neurosurg Anesthesiol 2003;15:140-143. 